\title{
Asymptomatic Malaria and Other Infections in Children Adopted from Ethiopia, United States, 2006-2011
}

\author{
Senait M. Adebo, Judith K. Eckerle, \\ Mary E. Andrews, Cynthia R. Howard, \\ Chandy C. John
}

We screened 52 children adopted from Ethiopia for malaria because they had previously lived in a disease-endemic region or had past or current hepatomegaly or splenomegaly. Seven $(13.5 \%)$ children had asymptomatic malaria parasitemia by microscopy $(n=2)$ or PCR $(n=5)$. Our findings suggest that adoptees at risk for asymptomatic malaria should be screened, preferably by PCR.

I nternational adoptees are at increased risk for infectious diseases (1). During 2007-2012, Ethiopia was 1 of the top 5 countries of origin for children who were adopted by persons in the United States (2), but few studies have been published on children from Ethiopia who were adopted by persons in the United States (3). Malaria caused by Plasmodium falciparum, P. vivax, and, less frequently, $P$. ovale is endemic to several regions in Ethiopia (4). Children adopted from Ethiopia are often living in orphanages in Addis Ababa, an area free of malaria, at the time of their adoption, but they may have lived in a malaria-endemic area before their transfer to the orphanage. The prevalence of asymptomatic malaria parasitemia among these children is not known.

\section{The Study}

We reviewed medical records of all children adopted from Ethiopia and seen at the University of Minnesota International Adoption Clinic (Minneapolis, MN, USA) during February 2006-June 2011 for results of standard infectious disease screening tests recommended by the American Academy of Pediatrics: tuberculosis (by tuberculin skin test or, in children $\geq 5$ years old, by interferon-g release assay); intestinal parasites (fecal testing for ova, parasites, and Giardia intestinalis antigen); hepatitis $\mathrm{B}$ or $\mathrm{C}$ virus; $\mathrm{HIV}$; and syphilis (5). Children were screened for hepatitis A virus at the discretion of the physician seeing the patient

Author affiliations: Children's Hospital of Philadelphia,

Philadelphia, Pennsylvania, USA (S.M. Adebo); University of Minnesota, Minneapolis, Minnesota, USA (J.K. Eckerle, M.E. Andrews, C.R. Howard, C.C. John); Indiana University, Indianapolis, Indiana, USA (C.C. John)

DOI: http://dx.doi.org/10.3201/eid2107.141933 and for malaria by blood smear or PCR if they met screening criteria (i.e., history of living in a malaria-endemic region or a history of or current evidence of splenomegaly or hepatomegaly). The study was reviewed and approved by the University of Minnesota Institutional Review Board.

During the period studied, 255 international adoptees from Ethiopia were seen at the clinic. Adoptees' mean age at medical evaluation was 2.8 years (range 3.4 months-14.9 years); 148 (58\%) were female and 107 (41.9\%) were male. All 255 children were asymptomatic for malaria, but 52 met malaria screening criteria and were tested by peripheral blood smear $(n=24)$, PCR $(n=24)$, or both $(n=4)$. Of the 52 children, $7(13.5 \%)$ had blood smear ( 2 children) or PCR ( 5 children) results positive for Plasmodium species. Table 1 outlines the sensitivity, specificity, and negative and positive predictive values of medical history questions and physical exam signs for asymptomatic malaria. The 2 children with a positive blood smears had low parasite densities $(<0.1 \%)$, and the species could not be identified. These 2 children were treated before PCR testing was available. Subsequently, PCR became the preferred firstline diagnostic test, and 5 infections were diagnosed on the basis of PCR results: 3 P. vivax, 1 P. falciparum, and 1 mixed $P$. vivax and $P$. falciparum. Among the 7 children with parasitemia, 2 had a palpable spleen tip, 2 had a hemoglobin level of $<11 \mathrm{~g} / \mathrm{dL}$ (reference 11-15 g/dL), and none had thrombocytopenia. All children with a positive blood smear or PCR result were treated: atovaquone/proguanil for $P$. falciparum infections, chloroquine followed by primaquine for $P$. vivax infections, and atovaquone/proguanil followed by primaquine for the mixed infection and infections with no species identified.

In addition to the malaria results, of 217 children tested for intestinal parasites, $96(44.2 \%)$ had positive results; Giardia intestinalis flagellates were most common (n $=75,34.6 \%$ ), followed by Blastocystis hominis protozoa $(\mathrm{n}=34,15.7 \%)$ (Table 2). Evidence of tuberculous infection was found in $49(27.1 \%)$ children, hepatitis A virus in $14(8.7 \%)$, hepatitis B virus in $6(2.6 \%)$, and HIV in 1 $(0.5 \%)$ (Table 2$)$.

\section{Conclusions}

In this study, we show that $7(13.5 \%)$ of 52 adoptees from Ethiopia who had lived in a malaria-endemic region or had hepatomegaly or splenomegaly by clinical history or on physical examination had asymptomatic malaria 
Table 1. Value of certain characteristics or findings for predicting asymptomatic malaria parasitemia in children adopted from Ethiopia who were seen at the University of Minnesota International Adoption Clinic, Minneapolis, Minnesota, USA, 2006-2011*

\begin{tabular}{|c|c|c|c|c|c|c|}
\hline \multirow[b]{2}{*}{ Characteristic or finding } & \multicolumn{2}{|c|}{ Malaria, no. (\%) } & \multirow{2}{*}{$\begin{array}{l}\text { Sensitivity, } \\
\%\end{array}$} & \multirow{2}{*}{$\begin{array}{l}\text { Specificity, } \\
\%\end{array}$} & \multirow{2}{*}{$\begin{array}{l}\text { PPV, } \\
\%\end{array}$} & \multirow{2}{*}{$\begin{array}{c}\text { NPV, } \\
\%\end{array}$} \\
\hline & Positive, $\mathrm{n}=7 \dagger$ & Negative, $\mathrm{n}=45$ & & & & \\
\hline History of hepatomegaly & 0 & $1(2.2)$ & 0 & 97.8 & 0 & 86.3 \\
\hline History of splenomegaly & $3(42.8)$ & $2(4.4)$ & 42.8 & 95.6 & 60.0 & 91.5 \\
\hline Presence of splenomegaly during examination & $2(28.6)$ & $3(6.7)$ & 28.6 & 92.3 & 40.0 & 89.4 \\
\hline Presence of hepatomegaly during examination & $1(14.3)$ & $7(15.6)$ & 14.3 & 84.4 & 12.5 & 86.4 \\
\hline $\begin{array}{l}\text { History of splenomegaly or presence during } \\
\text { examination }\end{array}$ & $3(42.8)$ & $4(8.9)$ & 42.8 & 91.1 & 42.9 & 91.1 \\
\hline Hemoglobin level of $<11 \mathrm{~g} / \mathrm{dL}$ & $2(28.6)$ & $6(13.3)$ & 28.6 & 87.7 & 25.0 & 88.7 \\
\hline
\end{tabular}

*NPV, negative predictive value; PPV, positive predictive value.

†Children who were malaria-positive by blood smear or PCR testing

parasitemia. We also confirm the findings of previous studies that showed high rates of infection with intestinal parasites (particularly G. intestinalis flagellates) (3), latent tuberculosis (3), and hepatitis A virus (6) in adoptees from Ethiopia.

The rate of asymptomatic malaria parasitemia in international adoptees is not known. As adoptions increase from countries in sub-Saharan Africa and other countries with areas of potential malaria transmission, such as India and Haiti, malaria screening will need to be considered for the adopted children. On the basis of the current data, we believe reasonable first-line criteria for malaria screening in international adoptees are residence in a malaria-endemic country plus either lack of documentation that the child lived for his or her whole life in a region of that country that was malaria free (e.g., Addis Ababa in Ethiopia) or past or current splenomegaly. However, a limitation of our study is that we used essentially these criteria to screen, and the prevalence of asymptomatic malaria might have differed if we used different criteria. For example, we did not screen all children with anemia (hemoglobin level of $<11 \mathrm{~g} / \mathrm{dL}$ ); because malaria is a leading cause of anemia in malariaendemic areas, anemia may be a useful additional screening criterion for malaria.

For over a century, microscopy has been the standard for documentation of malaria infection in persons with clinical malaria, but PCR has greater sensitivity for detection of low-level parasitemia (7) and is now a field standard for detection of asymptomatic parasitemia (8). Multiplex PCR also enables testing and identification of all 5 Plasmodium species that cause disease in humans and can provide species identification at low levels of parasitemia. In our study, microscopy testing on 2 children failed to determine the malaria species, a common difficulty in persons with lowlevel parasitemia. Without knowing the malaria species, we had to treat the children for both P. falciparum and P. vivax infection, which involved testing for glucose-6-phosphate dehydrogenase deficiency and treatment with multiple antimalarial medications. Knowledge of the prevalent species in immigrants from a specific area can also inform public health efforts and prophylaxis planning for travelers to that area. For these reasons, PCR is likely the test of choice for detection of asymptomatic parasitemia in children adopted from malaria-endemic areas.

For 3 reasons, we treated all adopted children with asymptomatic parasitemia, whether detected by PCR or microscopy. First, a diagnosis of malaria could be missed if these children became febrile. After their adoption, many lived in areas in which malaria is rarely if ever seen, so the diagnosis of malaria might not be considered. Second, malaria can cause severe disease, so a missed diagnosis could have major health consequences for the child. Third, most antimalarial medications have a low toxicity, so treatment is not a danger to the child.

\begin{tabular}{lcc}
\hline $\begin{array}{l}\text { Table 2. Prevalence of infectious diseases in children adopted from Ethiopia who were seen at the University of Minnesota } \\
\text { International Adoption Clinic, Minneapolis, Minnesota, USA, 2006-2011 }\end{array}$ \\
\hline Infection & No. screening results available & No. (\%) positive \\
\hline Intestinal parasites & 217 & $96(44.2)^{*}$ \\
Tuberculosis & 181 & $49(27.1) \dagger$ \\
Malaria & 52 & $7(13.5)$ \\
Hepatitis A virus & 161 & $14(8.7)$ \\
Hepatitis B virus & 233 & $6(2.6)$ \\
Syphilis & 215 & $0 \dagger \ddagger$ \\
Hepatitis C virus & 219 & $0 \dagger \neq$ \\
HIV & 218 & $1(0.5) \ddagger$
\end{tabular}

${ }^{*}$ Evidence of infection with $>1$ of the following: Giardia intestinalis flagellates $(n=75,34.6 \%)$, Blastocystis hominis protozoa $(n=34,15.7 \%)$

Hymenolepsis nana tapeworms $(n=2,0.9 \%)$, Dientamoeba fragilis protozoa $(n=2,0.9 \%)$, Ascaris lumbricoides roundworms $(n=2,0.5 \%)$, or Trichuris trichiura roundworms $(0.5 \%)$.

†By tuberculin skin testing (induration $\geq 10 \mathrm{~mm} ; n=46)$, interferon- $\gamma$ release assay $(n=1)$, or both $(n=2)$. Latent tuberculosis infection was diagnosed in 48 children. Tuberculosis disease was diagnosed initially in 1 , but was later reassessed as latent tuberculosis infection; medications for disease were stopped after 4 months of treatment.

fInitial screening tests results were positive in 2 additional children, but confirmatory tests were negative. 
We now use PCR to screen asymptomatic children from malaria-endemic areas. We recommend this method for centers with rapid access to PCR for all 5 human Plasmodium species because increased sensitivity of detection is more important than rapid detection in asymptomatically infected children. However, any symptomatic child (e.g., a child with fever) must have microscopy or rapid diagnostic testing performed immediately, because these results are typically available quickly and can guide immediate decisions regarding treatment.

In summary, this study shows that children adopted from Ethiopia who lived in malaria-endemic regions of Ethiopia or had past or current splenomegaly are at risk for asymptomatic $P$. falciparum and $P$. vivax parasitemia. The study findings support the importance of obtaining a careful history to determine malaria risk and conducting PCR screening for asymptomatic infection in children with the noted risk factors. These findings may also be relevant to children adopted from other malaria-endemic countries.

Dr. Adebo works as a hospitalist pediatrician at the Children's Hospital of Philadelphia. Her primary research interests are global health and international adoption issues.

\section{References}

1. Hostetter MK. Infectious diseases in internationally adopted children: the past five years. Pediatr Infect Dis J. 1998;17:517-8. http://dx.doi.org/10.1097/00006454-199806000-00018
2. US Department of State. Intercountry adoption. Statistics. Washington (DC): The Department [cited 2013 Apr 24]. http://adoption.state.gov/about_us/statistics.php

3. Miller LC, Tseng B, Tirella LG, Chan W, Feig E. Health of children adopted from Ethiopia. Matern Child Health J. 2008;12:599-605. http://dx.doi.org/10.1007/s10995-007-0274-4

4. Centers for Disease Control and Prevention Health information for international travel. The yellow book 2012. Atlanta: The Centers [cited 2013 Apr 23]. http://wwwnc.cdc.gov/travel/page/ yellowbook-2012-home.htm

5. American Academy Pediatrics Committee on Infectious Diseases. Medical evaluation of internationally adopted children for infectious diseases. In: Pickering LK, Baker CJ, Kimberlin DW, editors. Red book: report of the Committee on Infectious Diseases. 29th ed. Elk Grove Village (IL): The Academy; 2012. p. 192-200.

6. Raabe VN, Sautter C, Chesney M, Eckerle JK, Howard CR, John CC. Hepatitis A screening for internationally adopted children from hepatitis A endemic countries. Clin Pediatr (Phila). 2014;53:31-7. http://dx.doi.org/10.1177/0009922813505903

7. Snounou G, Bourne T, Jarra W, Viriyakosol S, Brown KN. Identification and quantification of rodent malaria strains and species using gene probes. Parasitology. 1992;105:21-7. http://dx.doi.org/10.1017/S0031182000073649

8. Menge DM, Ernst KC, Vulule JM, Zimmerman PA, Guo H, 3John CC. Microscopy underestimates the frequency of Plasmodium falciparum infection in symptomatic individuals in a low transmission highland area. Am J Trop Med Hyg. 2008;79:173-7.

Address for correspondence: Chandy C. John, Ryan White Center for Pediatric Infectious Disease and Global Health, Indiana University School of Medicine, 1044 W Walnut St, Rm 402-C, Indianapolis, IN 46202, USA; email: chjohn@iu.edu

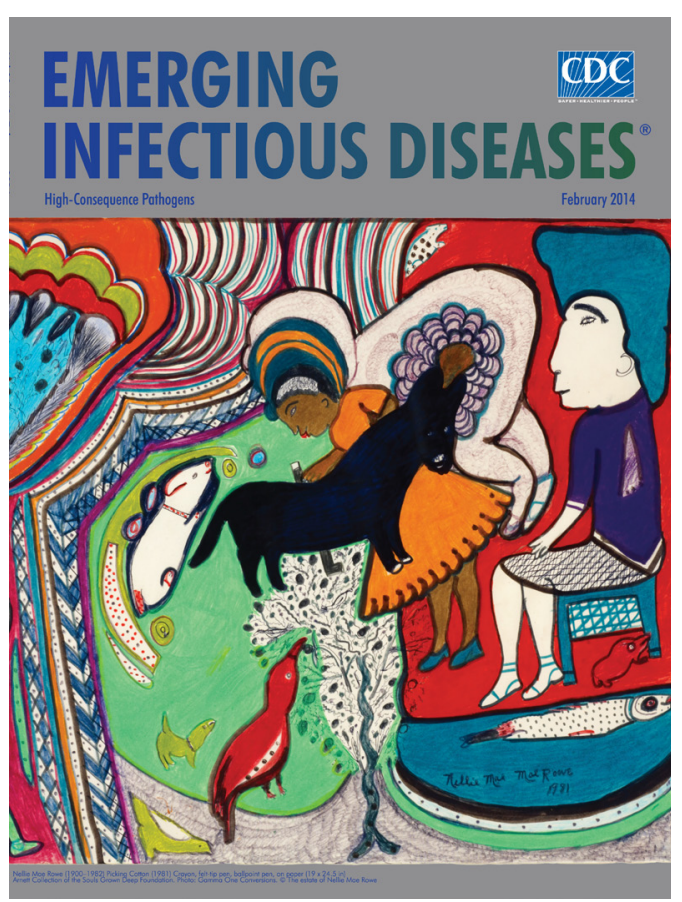

\section{February 2014: High-Consequence Pathogens} Including:

- Poxvirus Viability and Signatures in Historical Relics

- Novel Paramyxovirus Associated with Severe Acute Febrile Disease, South Sudan and Uganda, 2012

- Subtyping Cryptosporidium ubiquitum, a Zoonotic Pathogen Emerging in Humans

- Genomic Variability of Monkeypox Virus among Humans, Democratic Republic of the Congo

http://wwwnc.cdc.gov/eid/content/20/2/contents.htm 